\title{
Diagnostic Accuracy of Axillary Ultrasound for Prediction of Axillary Pathologic Response after Neoadjuvant Treatment in Breast Cancer
}

\author{
Ilhan Tasdöven', Rabiye Uslu Erdemir², Güldeniz Karadeniz Çakmak* \\ 'Zonguldak Bulent Ecevit University, The School of Medicine, Department of Surgery, Kozlu, Zonguldak, Turkey \\ 2Zonguldak Bulent Ecevit University, The School of Medicine, Department of Nuclear Medicine, Kozlu, Zonguldak, Turkey
}

${ }^{*}$ Corresponding author: Güldeniz Karadeniz Çakmak, FACS, FEBS Professor of Surgery Zonguldak Bulent Ecevit University School of Medicine

Chair, General Surgery Department Director, Breast and Endocrine Unit Kozlu, Esenköy, Zonguldak, Turkey, 67600 E-mail: gkkaradeniz@yahoo.com

\section{Rezumat}

Acuratețea diagnosticului prin ecografie axilară pentru prezicerea răspunsului patologic axilar după tratamentul neoadjuvant al cancerului de sân

Context: In era terapiei neoadjuvante (NAT), prezicerea cu acuratețe a răspunsului patologic este o mare provocare, care ar putea influența abordarea chirurgicală pentru sân şi axilă. Stadializarea axilară prin metode imagistice a fost folosită ca adjuvant mult timp, cu diferite rate de precizie raportate. Cu toate acestea, rolul ecografiei axilare preoperatorii (AUS) la pacienții cu N0 clinic după NAT este controversat. Principalul scop al acestui studiu a fost de a evalua precizia AUS efectuată preoperator în identificarea răspunsului complet patologic (ypCR = ypT0, ypN0) după NAT.

Metode:A fost efectuată o analiză retrospectivă a unei baze de date menținute prospectiv dintr-o singură instituție pentru identificarea pacienților cu cancer de sân tratați cu NAT. Doar acei pacienți la care s-a efectuat AUS şi 18F-FDG-PET / CT înainte şi după NAT cu documentarea răspunsului clinic şi radiologic au fost incluşi pentru analiza prognosticului.

Rezultate: Din 253 pacienți consecutivi cu cancer de sân invaziv, stadiul axilar ypN0 a fost atins la $67,19 \%$. La 11,23\% pacienți cu ynon-pCR, AUS nu a detectat prezența bolii reziduale, dintre care $80 \%$ erau ITC şi micrometastaze. Macrometastaza a fost prezentă în 21,73\% (55/253) din cazuri, 98,18\% (54/55) din care a fost identificată de AUS. Precizia generală pentru pCR axilar s-a dovedit a fi de 89,32\% pentru AUS şi 76,28\% pentru 18-FDG-PET / CT. Rata 
fals negativă (FNR) a AUS şi 18-FDG-PET / CT a fost de 12,04\% şi respectiv 15,59\%. PPV al AUS a fost mai mare pentru tumorile luminal-like (87,69\%), în timp ce subtipurile HER-2 pozitive (100\%) şi triplu negative $(93,47 \%)$ au avut NPV mai mare.

Concluzii:AUS este un instrument util ce are potențialul de a prezice cu exactitate prezența pCR la mai mult de $80 \%$ dintre pacienți după NAT. Cu toate acestea, în cazurile de ITC reziduale şi micrometastaze, precizia ecografiei ar trebui interogată cu prudență.

Cuvinte cheie: neoadjuvant, axilă, ecografie, PET / CT

\section{Abstract}

Background: In the era of NAT, to accurately predict pathologic response is a great challenge, which might influence surgical approach for breast and axilla. Axillary staging via imaging methods as an adjunct have long been used with various reported accuracy rates. However, the role of preoperative axillary ultrasonography (AUS) in clinical N0 patients after NAT is still controversial. The primary goal of the present study was to evaluate the precision of preoperative AUS for identifying pathologic complete response (ypCR = ypT0, ypN0) after NAT.

Methods: A single-institution, retrospective review of a prospectively maintained database was analyzed to identify breast cancer patients treated with NAT. Only those patients who underwent AUS and 18F-FDG-PET/CT before and after NAT with documentation of clinical and radiological response were incorporated for outcome analysis.

Results: In 253 consecutive invasive breast cancer patients axillary ypN0 disease was achieved in $67.19 \%$. In $11.23 \%$ ynon-pCR patients AUS failed to detect residual disease presence $80 \%$ of which were ITCs and micrometastases. Macrometastasis was present in 21.73\% (55/253) of the cases $98.18 \%(54 / 55)$ of which was determined by AUS. Overall accuracy for axillary pCR was found to be $89.32 \%$ for AUS and $76.28 \%$ for 18 -FDG-PET/CT. The false negative rate (FNR) of AUS and 18-FDG-PET/CT was $12.04 \%$ and $15.59 \%$, respectively. The PPV of AUS was higher in Luminal-like tumors (\%87.69), whereas HER-2 positive (\%100) and triple-negative (93.47\%) subtypes had higher NPV.

Conclusions:AUS is a beneficial tool with the potential of accurate prediction of $\mathrm{pCR}$ in more than $80 \%$ of patients following NAT. Nevertheless, in cases of residual ITCs and micrometastasis the accuracy of US should be interrogated cautiously.

Key words: neoadjuvant, axilla, ultrasound, PET/CT

\section{Introduction}

Neoadjuvant therapy (NAT) is the preferred option of management in locoregionally advanced and selected cases with early-stage breast cancer, currently (1). In the era of NAT, to accurately predict pathologic response is a great challenge, which might influence surgical approach for breast and axilla. Pathologic complete response (pCR) not only allows breast conservation but is a crucial prognostic factor, as well (2). Therefore, pCR became a recom- mended surrogate endpoint on overall survival period with a predictive capacity mainly depending on molecular subtypes. The other crucial prognostic determinants in the outcome of invasive breast cancer has long been defined as axillary lymph node status. The accurate staging of which is of paramount importance to make appropriate recommendations and to tailor individualized treatments. Similar to breast cancer management, in last decades there has been a great paradigm shift to stage axilla from radical dissections to more 
conservative approaches. With the wellevidenced data reporting higher morbidity rates regarding lymphedema after axillary lymph node dissection (ALND), sentinel lymph node biopsy (SLNB) has been the major goal to stage axilla for each breast cancer patient and replaced ALND in appropriate cases $(3,4)$. SLNB has been employed as the preferred choice of care for axillary staging in clinically node-negative (cN0) cases for more than thirty years (5). Nevertheless, for locally advanced patients with clinically positive axillary metastasis (cN1) at the time of initial diagnosis, SLNB is not an option, which is one of the main reasons for this group of patients to be optimal candidates for preoperative systemic treatment. NAT not only serves to de-escalate breast surgery but also provides the advantage of omitting axillary dissection for complete responders turned out to be clinically and SLNB negative after NAT up to $52.5 \%(6-8)$. However, de-escalation of axillary surgery from complete ALND to SLNB to stage axilla seems not to be enough to prevent lymphedema with a reported rate varying from 3-8\% with SLNB alone and $5-14 \%$ with SLNB plus axillary radiation therapy $(5,9,10)$. As SNLB is not riskfree regarding complications, a great attention in noninvasive methods of axillary staging aroused, particularly in the era of NAT and pathologic complete response $(11,12)$. Clinical examination with radiologic evaluation including ultrasound, mammography, breast magnetic resonance imaging (MRI) and various other diagnostic modalities such as positron emission tomography (PET) scans (18F-FDG$\mathrm{PET} / \mathrm{CT}$ ) could be performed to assess the response rate, relevant to institutional resources. However, a standard approach to evaluate pathologic response via imaging is not currently available. Diagnostic uncertainties led surgery to be the inevitable option to prove pCR in any case with radiologic and clinical CR with histopathologic evaluation of the specimen remaining as the gold standard to define response nature and rate. Nevertheless, the high pCR rates relevant to molecular subtypes began to question the leading role of surgery searching for imaging methods to accurately predict $\mathrm{pCR}$ without performance of invasive interventions. Axillary staging via imaging methods as an adjunct have long been used with various reported accuracy rates. Sonographic evaluation of the axilla is extensively employed at diagnosis for locoregional staging. Nevertheless, the reported sensitivity (27\%-94\%) and specificity (53\%-100\%) vary widely $(13,14)$. On the other hand, 18F-FDG$\mathrm{PET} / \mathrm{CT}$ do not reach sufficient sensitivity to be recommended in routine assessment for detecting residual disease after NAT $(15,16)$.

In this respect, the role of preoperative axillary ultrasonography (AUS) in clinical N0 patients after NAT is still controversial. With the current scientific discussions focusing on the question about the possibility of omission of in breast surgery in selected extreme responders to NAT, the primary goal of the present study was to evaluate the precision of preoperative AUS for identifying pathologic complete response (ypCR = ypT0, ypN0) after NAT. As a secondary endpoint the comparison with respect to 18 FDG-PET-CT and clinical physical examination was performed. The effect of molecular subtypes on sonographic prediction was also analyzed.

\section{Patients and Methods}

\section{Study Design}

A single-institution, retrospective review of a prospectively maintained database was analyzed to identify breast cancer patients treated with NAT.

\section{Patients \& Inclusion Criteria}

Patients with biopsy-proven non-metastatic invasive breast cancer who were decided to receive NAT by multidisciplinary tumor board were included. Only those patients who underwent AUS and 18F-FDG-PET/CT before and after NAT with documentation of clinical and radiological response were incorporated for outcome analysis.

\section{Outcomes}

Primary outcome of the current study was to 
analyze the diagnostic accuracy of AUS evaluation (negative predictive value) on detecting pathologic complete response $(\mathrm{ypCR}=\mathrm{ypT0}$, ypN0) in the axilla after NAT.

Secondary outcome included the evaluation of the precision of 18F-FDG-PET/CT for the same purpose and to determine the superiority of the modality which serves better after NAT as well as the, the estimations of in breast tumor response to NAC and correlation with axillary downstaging regarding molecular subtypes were analyzed.

\section{Procedures}

The eligible patients for inclusion at admission had AUS and 18F-FDG-PET/CT. Breast MRI imaging was not obligatory but permitted. Histopathologic diagnosis was confirmed by US-guided core biopsy and distant metastasis was ruled out by systemic screening in each patient. Tumors and patients with a pathologically confirmed N1 disease at initial diagnosis underwent ultrasound guided clip (Geotek PEEK $^{\circledR}$ titanium spiral) placement of metastatic lymph node which was excised during SLNB procedure before NAT initiation according to standard institutional protocol. NAT regimens were decided by institutional multidisciplinary tumor board after their initial diagnosis and staging at admission. After completing their NAC, each patient underwent clinical exam, AUS and 18F-FDG-PET/CT as minimum requirements to assess the clinical response and to rule out metastatic spread before surgery.

\section{Identification of Axillary Lymph Nodes Using B-mode AUS}

All patients received a B-mode ipsilateral and contralateral AUS before and after the completion of NAT (Fig. 1). As an institutional standard, in addition to radiologists, an experienced breast surgeon who performed the surgical operation did all study-related, real time B-mode AUS examinations both at pre, and post-NAC setting. All patients were scanned with 6 to $12-\mathrm{MHz}$ high-frequency linear array transducer (Hitachi HI Vision 5500 system, equipped with color Doppler; Hitachi, Tokyo, Japan). Axillary lymph nodes were interpreted, as "normal" if specific sonographic characteristics which were commonly associated with metastatic involvement were not present. The nodes with suspicious appearance were defined as "abnormal" and it was noted if no lymph node was visualized after NAT. On the basis of sonographic features defining morphologic appearance with relation to cortical and hilar status, the classification of the nodes were done accordingly: nodes with invisible hyperechoic cortex and with a hypoechogenic cortex thinner than $3 \mathrm{~mm}$ were accepted as normal. On the contrary, thicker hypoechogenic cortex $(\geq 3 \mathrm{~mm})$, hypoechogenic cortex with complete or focal lobulation and loss of echogenic fatty hilum in a hypoechogenic node were recorded as abnormal. Additionally, nodes with rounded shape, eccentric cortical thickening and long-to-short diameter ratio $\leq 2$ were deemed to be abnormal (17-22).
Figure 1. Diagnostic characteristics of AUS after NAT

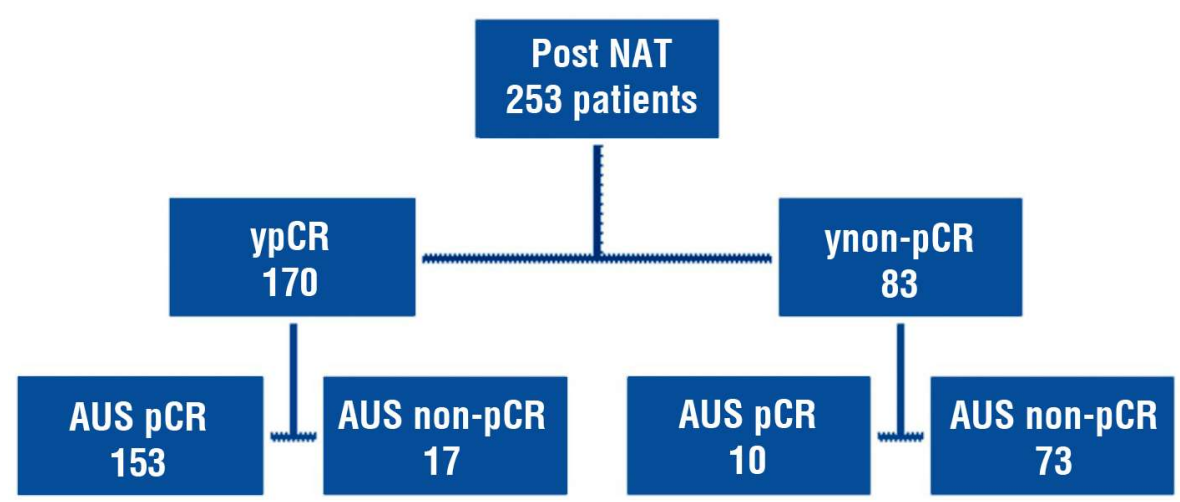

Post NAT

253 patients 


\section{Evaluation of Axillary Lymph Nodes by 18-FDG-PET-CT}

18F-FDG-PET/CT scans were performed to each patient at the initial diagnosis and after the completion of NAT. The same morphologic criteria defined as abnormal were applied to PET-CT evaluation. Focal 18F-FDG uptake with a greater intensity than that of normal background on PET image was accepted to be indicative for metastasis. Treatment response was classified as complete, partial, and none. Axillary nodes with normalized appearance were classified as not metastatic if there was lack of FDG activity, as suspicious if some of the suspicious features regressed, and as metastatic if there was no change in pre-NAT status or progression of the imaging appearance and nodes with increased FDG uptake and greater SUV values when compared to adjacent normal tissue (23).

\section{Surgical Management of the Axilla}

Patients were selected for SLNB based on the restaging following NAT. All patients with abnormal LN on AUS and a tissue diagnosis confirming the presence of metastasis were advised to have ipsilateral axillary dissection after NAT. SLNB was performed to patients with clinically and radiologically negative axilla with a technique of dual agent mapping via patent bule dye and filtered Technetium-99M sulfur radiocolloid, aiming to achieve at least 3 SLNs. In the morning of the operation, patients were injected radioactive isotope, 40 mbeq in the periareolar four quadrants of the breast and static and flow lymphoscintigraphic images were obtained. The operations were performed by a specialist breast surgeon and intraoperative real-time sonographic imaging was performed in each case. In the operating room after anesthetic induction patients received a $2 \mathrm{~mL}$ injection of isosulphan blue dye (Patent Blue 2.5\%, Gazi-Ankara, Turkey) sub-dermally in four quadrant fashion around periareolar region. Before making axillary incisions, intraoperative real time sonography was conducted to visualize the nodes marked with the clip and the clipped nodes were excised in all cases independent of being marked with the dye or radiotracer. The absence of the clip in the specimen radiography warranted a second look imaging to capture the overlooked lymph node. A gamma probe (Euoroprobe 3, Eckbolsheim, France) was used to identify SLNs. As the SLNB procedure completed, the number of SLNs gathered from each patient was noted. Frozen section analysis of SLN was standard per protocol. For positive cases complete axillary lymph node dissection was warranted at the initial surgery or as a secondary intervention in case of lymph node metastasis in permanent section analysis. Histopathological analysis with immunohistochemical staining were done to all surgical specimens.

\section{Assessment of Response to NAT}

Pathological complete response (pCR) was defined as the confirmation of absence of in-situ or invasive cancer cells in any axillary lymph nodes (ypN0) histopathologically. Post-NAT axillary lymph node status was termed as $\mathrm{yN}$ micromet. and yNitc when there were micrometastases and isolated tumor cells.

\section{Data}

Variables analyzed included age, body mass index, menopausal status, tumor diameter, grade, histologic type, hormone receptor status, HER2 expression, SLN detection rate, pathologically positive SLN, and completion axillary dissection. Intraoperative data included SLN localization, number of SLNs excised, and means of SLN identification. Surgical pathology was reviewed, and breast cancer staging was assigned based on the $8^{\text {th }}$ edition of the American Joint Committee on Cancer (AJCC) staging system. Positive predictive value (PPV), negative predictive value (NPV), sensitivity, specificity and accuracy of preoperative AUS and 18-FDG PET to predict residual nodal disease were calculated. 


\section{Statistical Analysis}

Categorial variables were presented as number and percentage. Mean and standard deviation values and median with interquartile range was also reported. Regarding study outcomes, AUS and 18FDG PET/CT data were compared to results of SLNs via histopathologic assessment. The diagnostic accuracy of AUS and 18FDG PET/CT for axillary residual disease prediction was given as negative predictive value (NPV). The FNR of the AUS was calculated due to the proportion of node-positive cases (ypN+) at the permanent histopathologic report with negative AUS. Negative predictive value (NPV) was calculated according to the standard formula: $\mathrm{TN} / \mathrm{TN}+\mathrm{FN}$.

\section{Results}

\section{Cohort Characteristics}

Between January 2014 and December 2018, 253 consecutive invasive breast cancer patients treated with NAT and had standard breast and axillary nodal surgery were identified from a prospective database of breast cancer cases diagnosed at Zonguldak Bulent Ecevit University The School of Medicine (Zonguldak, TR) and the data collected was retrospectively analyzed. The demographic, clinical and histologic characteristics of the cohort are summarized in Table 1. Of those patients, final histopathologic analysis confirmed that 102 (40.3\%) patients achieved pCR and all of whom had a corresponding clinical complete response. Tables 2 and 3 show the tumor clinical and imaging features, response to NAT and the type of surgery performed on breast and axilla.

\section{Assessment of $p C R$ via US and 18F-FDG- PET/CT in cNO Patients before NAT}

Among 134 patients with clinical negative axilla and initial nodal US demonstrating N0 disease, 56 patients $(41.8 \%)$ had a breast pCR and all of these cases showed no evidence of clinical and sonographic axillary lymph node metastases after NAT. All of these patients underwent SLNB, the median number of
Table 1. The demographic, clinical and histologic characteristics

\begin{tabular}{|c|c|}
\hline & Study Population $(n=253) n(\%)$ \\
\hline Age (years) & 23-76 (median 54 y) \\
\hline \multicolumn{2}{|l|}{ Menopausal status } \\
\hline Premenopause & $140(55.3)$ \\
\hline Postmenopause & $113(44.7)$ \\
\hline \multicolumn{2}{|l|}{ Histologic type } \\
\hline Ductal & $218(86.2)$ \\
\hline Lobular & $35(13.8)$ \\
\hline \multicolumn{2}{|l|}{ Molecular subtype } \\
\hline Luminal $A$ & $30(11.8)$ \\
\hline Luminal B & $118(46.6)$ \\
\hline Her-2 + & $40(15.8)$ \\
\hline Triple negative & $65(25.8)$ \\
\hline \multicolumn{2}{|l|}{ Grade } \\
\hline Grade 1 & $25(9.8)$ \\
\hline Grade 2 & $40(15.7)$ \\
\hline Grade 3 & $166(65.8)$ \\
\hline Unknown & $22(8.7)$ \\
\hline \multicolumn{2}{|l|}{ Ki-67 } \\
\hline \multicolumn{2}{|l|}{ Side } \\
\hline Left & $108(42.6)$ \\
\hline Right & $145(57.4)$ \\
\hline \multicolumn{2}{|l|}{ Focality } \\
\hline Unifocal & $204(80.5)$ \\
\hline Multifocal & $35(13.8)$ \\
\hline Multicentric & $9(3.5)$ \\
\hline Unknown & $5(2.1)$ \\
\hline
\end{tabular}

Table 2. Clinical and imaging outcomes

\begin{tabular}{lcc}
\hline & $\begin{array}{c}\text { Pre NAT staging } \\
(\mathbf{n = 2 5 3 )} \mathbf{( \% )}\end{array}$ & $\begin{array}{c}\text { Post NAT staging } \\
(\mathbf{n = 2 5 3 )} \mathbf{( \% )}\end{array}$ \\
\hline $\begin{array}{l}\text { Clinical exam positive nodes } \\
\text { Yes }\end{array}$ & $119(47.03)$ & $61(24.11)$ \\
No & $134(52.96)$ & $192(75.88)$ \\
Unknown & 0 & 0 \\
\hline AUS positive nodes & & \\
Yes & $132(52.17)$ & $100(39.52)$ \\
No & $121(47.82)$ & $153(60.47)$ \\
Unknown & 0 & 0 \\
\hline PET/CT positive nodes & & \\
Yes & $98(38.73)$ & $116(45.84)$ \\
No & $121(47.82)$ & $127(50.19)$ \\
Suspicious & $34(13.43)$ & $10(3.95)$ \\
\hline
\end{tabular}

Table 3. Surgery - final pathology

\begin{tabular}{lc}
\hline & Study cohort $(\mathbf{n}=\mathbf{2 5 3}), \mathbf{n}(\%)$ \\
\hline Breast Surgery & $194(77.7)$ \\
BCS & $59(23.3)$ \\
Mastectomy & $170(67.2)$ \\
\hline Axillary Surgery & $83(32.8)$ \\
SLNB & \\
ALND & $107(42.3)$ \\
\hline Breast pathology & $146(57.7)$ \\
yT0 (including DCIS) & \\
yT1-T3 & $170(67.2)$ \\
\hline Axillary pathology & $13(5.1)$ \\
yN0 & $15(5.9)$ \\
yN ITC & $55(21.7)$ \\
yN micromet. & $102(40.2)$ \\
yN1-3 &
\end{tabular}


harvested sentinel nodes was 4 (IQR: 2-5). Of these, frozen section analysis revealed suspicion for malignancy in 4 patients which turned out to be benign in permanent section and ITCs or micrometastases was determined in totally 20 (14.9\%) and micrometastases was found in 21 (15.6\%) out of 134 patients. Intraoperative US determined in breast pCR in all 56 patients and AUS accurately identified pCR in $96.4 \%$ $(54 / 56)$ of these cases. 18F-FDG-PET/CT identified breast pCR in $94.6 \%(53 / 56)$ and axillary pCR in $89.3 \%(50 / 56)$ of cases. For patients who were clinically N0 at initial diagnosis and remained clinically N0 post-NAT, AUS accurately predicted axillary pCR in 89 out of 93 patients (95\%) who are confirmed to have pCR via SLNB. FNR of AUS was $9.75 \%$.

\section{Assessment of pCR via US and 18F-FDG- PET/CT in cN1 Patients before NAT}

For 119 patients with initially clinically and pathologically nod positive disease, 77 (64.75\%) patients had pCR in the axilla. 88.2\% (45/51) of patients with breast pCR had axillary pCR disease after NAT. ITCs or micrometastases was determined in totally $8(6.7 \%)$ and micrometastases in $34(28.5 \%)$ out of 119 patients. AUS accurately predicted pCR in 83.1\% (64 out of 77) of patients. In 42 axillary ynon-pCR patients AUS and PET-CT detected residual disease presence in $85.2 \%$ and $88 \%$ of patients, respectively. The sensitivity, specificity, positive predictive value and negative predictive value to predict axillary ypCR for AUS was $83 \%$, $85 \%, 91 \%$ and $73 \%$. FNR of AUS was $14.28 \%$.
However, 18F-FDG-PET/CT correctly identified pCR in 52 out of 77 patients $(67.5 \%)$ who were converted from $\mathrm{cN} 1$ to ypN0. The sensitivity, specificity, positive predictive value and negative predictive value for $18 \mathrm{~F}-\mathrm{FDG}-\mathrm{PET} / \mathrm{CT}$ was $67 \%, 66 \%, 78 \%$ and $53 \%$ (Fig. 2 ).

\section{Evaluation of Overall $p C R$ via $U S$ and $18 F-F D G-P E T / C T$}

Axillary ypN0 disease was achieved in 170 (67.19\%) patients. In 10 out of $83(11.23 \%)$ ynon-pCR patients AUS failed to detect residual disease presence, $8(80 \%)$ of which were ITCs and micrometastases. Micrometastases was present in $21.73 \%(55 / 253)$ of the cases. AUS determined macrometastatic disease in 98.18\% (54/55). Overall sensitivity, specificity, PPV and NPV for prediction of overall pCR after NAC was found to be $89 \%, 92 \%, 88 \%, 92 \%$ for US and $82 \%, 79 \%, 73 \%, 86 \%$ for $18 \mathrm{~F}-\mathrm{FDG}$ PET/CT, respectively. The PPV of AUS for predicting axillary status was $81.11 \%$ and for 18 FDG-PET-CT was $60.5 \%$. Overall accuracy for axillary pCR was found to be $89.32 \%$ for AUS and $76.28 \%$ for 18 -FDG-PET/CT. The false negative rate (FNR) of AUS and 18-FDGPET/CT was $12.04 \%$ and $15.59 \%$, respectively.

\section{Evaluation of Axillary pCR Regarding Molecular Subtypes}

Tumor biology is the mainstay of response to NAT. Accordingly, axillary shrinkage was also calculated for the various molecular subtypes. Seventy-seven patients (64.7\%) patients with

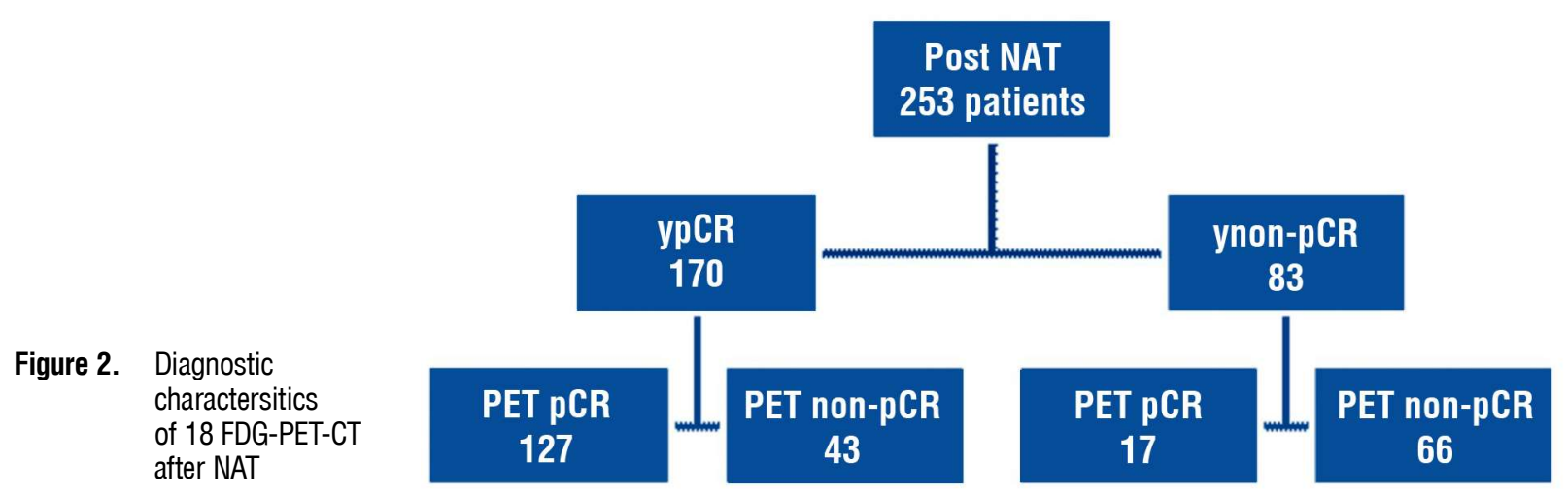


N1 disease experienced axillary downstaging after NAT. In all cohort, by molecular subtype $16.65 \%$ (5/30) in Luminal A, 66.94\% (79/118) in Luminal B, $95 \%$ (38/40) in HER-2 + and $73.8 \%(48 / 65)$ in triple negative breast tumors was ypN0. The PPV of AUS was higher in Luminal-like tumors (\%87.69), whereas HER-2 positive (\%100) and triple-negative (93.47\%) subtypes had higher NPV (Table \). The variation of accurate response prediction was not evident for PET-CT regarding molecular phenotype.

\section{Follow-up Data}

Three patients were lost to follow-up. Three $(1.18 \%)$ patients had an ipsilateral breast recurrence at a median period of 25 months after diagnosis. One $(0.3 \%)$ patient had contralateral breast cancer. Two (0.7\%) patients had isolated axillary recurrence (both of whom were $\mathrm{cN} 1$ at diagnosis and converted to cN0 after NAT), one (0.3\%) patient developed bilateral supraclavicular node metastasis, none of these patients died.

\section{Discussion}

Individualized breast cancer management becomes an established paradigm currently. Nevertheless, tailored axillary approach persists as a matter of debate, particularly after NAT. The major reason responsible is the absence of accurate staging method with acceptable validity. In accordance, noninvasive imaging techniques with higher predictive power about axillary status evoked great enthusiasm above researchers.

Surgical approach to the breast after NAT is a well-established issue that is tailored based on the pattern and the rate of response

Table 4. Diagnostic characteristics of AUS according to molecular subtype

\begin{tabular}{lccc}
\hline $\begin{array}{l}\text { Molecular Subtype } \\
\text { (N) }\end{array}$ & $\begin{array}{c}\text { PPV* } \\
\text { (\%) }\end{array}$ & $\begin{array}{c}\text { NPV** } \\
\text { (\%) }\end{array}$ & $\begin{array}{c}\text { Accuracy } \\
\text { (\%) }\end{array}$ \\
\hline Luminal like tumors (148) & 87.69 & 91.5 & 89.86 \\
\hline HER-2 (+) (40) & 33.3 & 100 & 90 \\
\hline Triple negatives (65) & 73.68 & 93.47 & 87.69 \\
\hline
\end{tabular}

to treatment. However, there is no global consensus about the management of the axilla which is still mastered by the nodal status at initial diagnosis. Either clinically nodenegative or positive, breast cancer patients before NAT may harbor nodal metastases up to $88 \%$ depending on tumor biology and patient factors at the completion of the protocol (24). The lower nodal positivity rate reported in randomized trials and institutional series in patients treated with NAT compared to those experiencing initial surgery raises interest about less invasive but more accurate axillary staging strategies after NAT. The last three decades witnessed a significant paradigm shift in nodal evaluation techniques, with a trend toward more conservative and less radical dissections. SLNB became the gold standard method for nodal staging in patients with clinically node-negative (cN0) disease after NSABP B-32 (5). Later on, ACOSOG Z0011 trial confirmed the safety of SLNB alone in conjunction with adjuvant wholebreast radiation for women with less than three positive SLNs and tumors smaller than $5 \mathrm{~cm}$. undergoing breast conservation, thereby omitting ALND for 84\% of SLNB-positive cases (25). However, a significant concern in identifying noninvasive and oncologically safe strategies to establish nodal status persists as a fact. The role of axillary imaging to identify disease in the axilla that may be down-staged in patients with initially $\mathrm{cN} 1$ disease remains uncertain. Clinical issues about the accuracy and false negative rate (FNR) of SLNB after NAT in initially node positive patients has been addressed via prospective studies reporting required circumstances to achieve the FNR below 10\%, which is the accepted upper cut off limit currently $(1,26-29)$. These trials recommended dual agent mapping (with radiocolloid and dye), at least three sentinel node removal and immunohistochemical analysis to increase the accuracy of SLNB in this specific population to overcome concerns about the long-term safety of this approach (26-29). However, the safety of SLNB after NAT as the standard procedure has been confirmed with 10-year follow-up data of 
cN1/2 patients who become cN0 after NAT without worse outcome (30). Moreover, various randomized trials have demonstrated that all these efforts to reduce FNR does not possess clinical significance regarding prognosis (31-33). In order to achieve the goal to have a FNR below $10 \%$, we applied standard institutional protocol for all our NAT patients, which includes clipping the positive node before NAT, mapping with dual agent and retrieving at least 3 SLNs with a median number of 4 in the presented series.

AUS has long been in clinical practice to assess the axilla as a part of the diagnostic evaluation in breast cancer. The major concerns about the nature of the sonography including operator-dependance has been partially eliminated via the superior efficacy for superficial structures when compared with other imaging modalities in the axilla and termed as accurate enough for routine clinical use (34). Additionally, AUS has the advantages of reproducibility, cost-effectiveness, real-time imaging, and lack of ionizing radiation (14). The results from the American College of Surgeons Oncology Group Z1071 Trial (Alliance) with a FNR of $9.8 \%$ with the combination of axillary ultrasound (AUS) and SLNB has been proposed to be acceptable for the adoption of SLNB surgery for women with node-positive breast cancer treated with NAT (17). Identifying residual nodal disease after NAT is one of the most enthusiastic and evolving issues promising revolutionary paradigm shift in clinical practice. AUS has been found to be beneficial for nodal response assessment (21). Nevertheless, most of the published data on the US features of regional nodes are from patient cohorts that did not receive NAT and a standardized lexicon with a validated categorization regarding pathologic features of lymph nodes that should be considered as positive after NAT does not exist. To date, no universally accepted guideline has been employed on imaging criteria for the abnormal lymph nodes. In the present study a second look AUS was performed by an experienced breast surgeon with breast US certification on the operation day after NAT in addition to radiologist's assessment and the nodes were classified as normal (yrN0) or abnormal (yrN1) regarding basic sonographic features, which provided quantitative analysis to decrease selection bias. Nevertheless, the FNR of AUS was found to be $12.04 \%$ in the presented series, which is in accordance with ACOSOG Z1071 trial (28). It merits consideration to emphasize that most of these cases were found to have ITC and micrometastases without macrometastasis which interrogates the efficiency of US for patients with $\mathrm{cN} 1$ before NAT and converted to cN0.

The axillary lymph node status determines the most appropriate treatment plan for individual patient. In literature, however, AUS has an unfavorable reputation with historically broad range of false-negative rates $(35,36)$. Accordingly, it has been considered neither sufficient, nor efficient to exclude axillary lymph node metastases. However, a 2011 meta-analysis by Houssami et al. reported a $79.6 \%$ sensitivity, $98.3 \%$ specificity, and $97.1 \%$ positive predictive value for AUS with FNA or core-needle biopsy (37). Moreover, recently, AUS has been reported to accurately exclude clinically significant axillary lymph node disease in patients with clinical T1-T2, N0 breast cancer and proposed AUS as an alternative to SLNB (38). In accordance with the abovementioned study, the current data confirms that the performance characteristics of AUS are excellent, with a NPV of $92 \%$ after NAC, which is superior to 18 FDG-PET-CT for cN0 patients. The higher sensitivity with the lower specificity of AUS to predict residual disease was demonstrated in literature comparing AUS with MRI and 18 FDG-PET$\mathrm{CT}$, in one of the largest trials US achiving the highest accuracy $(13,39,40)$. Similarly, when compared with 18 FDG-PET-CT, overall accuracy for axillary pCR was found to be higher for AUS (89.32\% vs $76.28 \%$ ) in our series. In a recent systematic review by Banys-Paluchowski et al. AUS was found to improve the prediction of axillary status after NAT in comparison to physical examination (41). In accordance, we determined that the result of AUS informing residual disease 
which was discordant to physical examination was confirmed via histopathologic analysis of SLNB in $15.41 \%$ of patients in our series, supporting the hypothesis that physical examination alone is not sufficient to accurately assess axilla after NAT and may lead to underdiagnosis. In $\mathrm{C}$ arm of the SENTINA trial, the rate of patients harboring one or more metastatic lymph nodes was $38 \%$ with initially node positive disease and converted to node-negative based on clinical examination and US after NAT (26). In our population with similar re-staging after NAT, axillary residual disease rate was $35.25 \%$. Our data demonstrated that the diagnostic accuracy of AUS should be interrogated separately for patients presented with $\mathrm{cN} 0$ and $\mathrm{cN} 1$ disease before NAT with a FNR of $9.75 \%$ and $14.28 \%$, respectively. The rate of ITCs and micrometastases on SLNs might be the rationale behind this issue, which is strongly dependent to the molecular subtypes of patients presented with axillary disease for whom the highest complete response rates could be achieved in HER-2 positive and triple negative cases. Accordingly, we support the idea that AUS might represent a potential alternative to SLNB for re-staging of the axilla in ypN0 breast cancer. This hypothesis about the role of AUS for axillary staging is being evaluated by currently ongoing trials, namely SOUND, INSEMA and BOOG (42-44). The accrual is currently completed in SOUND trial, in which patients with $\mathrm{T} 1$ breast cancer and negative AUS are being randomized to observation alone or to SLNB (42). Together with the data of ongoing INSEMA and BOOG 2013-08 trials, the omission of SLNB in clinically node negative patients would be on stage, however it worths notifying that the lack of pathologic lymph-node status data on adequate decision-making process about adjuvant treatments might be an obstacle. Moreover, the inter-observer variability of US with reported low sensitivity requiring great necessity of improving technical capabilities of diagnostic imaging which would be possible via the integration of artificial intelligence and radiomics to conventional diagnostic modalities, are the drawbacks to be addressed.

The accurate post-NAT axillary evaluation irrelevant to the status at diagnosis to decide on the optimal surgical approach is of paramount importance. As demonstrated in our series, $64.75 \%$ of patients with $\mathrm{cN} 1$ disease at presentation converted to $\mathrm{cN} 0$ and underwent SLNB for whom AUS was capable of predicting pCR in $83.1 \%$, superior to 18 FDG-PET-CT (67.5\%). This data is consistent with literature supporting the feasibility of SLNB after NAT regardless of axillary status at diagnosis $(45,46)$. Galimberti et al. reported 10-year follow-up data of their experience on SLNB after NAT with an axillary recurrence rate of $1.6 \%$ for $\mathrm{cN} 1-2$ patients who became cN0 post NAT and survived without disease (45) which is comparable with our data $(1.68 \%$ (2/119)). Moreover, no significant survival difference between the $\mathrm{cN} 0$ and $\mathrm{cN} 1$ (before NAT) patients who underwent SLNB was shown by Martinelli el al. (46).

Another important issue to be discussed about the response is the tumor biology which would directly impact the de-escalation of in breast and axillary surgery. A significant correlation of in breast and axillary complete response to NAT depending on molecular subtype, especially in HER-2 positive and triple negative tumors, has been reported in literature (47-49). In accordance with the data of Esgueva et al., in 94.39\% (101/107) of patients without residual disease in breast achieved axillary complete response in our series (47). $100 \%$ of patients with $\mathrm{cNO}$ and $88.1 \%$ of patients with $\mathrm{cN} 1$ who achieve breast complete response presented with ypN0 after NAT, similar to reported rates in literature (47-49). Accordingly, it might be rational to primary focus the discussion about omission of surgical axillary staging on this subgroup of patients. In HER-2 positive and triple negative tumors receiving NAT, ALND was found to be lower when compared to patients with primary surgery (50). Similarly, in our series, the best responders for either breast or axilla were Her-2 positive and triple negative tumors (92.5\% and 69.2\%, respectively). Hence, it is a matter of fact that patients with 
abovementioned molecular subtypes would extensively benefit from NAT and converted to ypN0 even if presented with clinically advanced axillary disease. Di Micco reported that AUS showed the highest accuracy (69.3\%) in re-staging axilla after NAT when compared to clinical examination (60\%), breast MRI $(64.6 \%)$ and 18 -FDG PET $(56 \%)$ with a staging power depending on tumor biology (39). In accordance, the accuracy of AUS $(89.32 \%)$ was superior to 18-FDG PET (76.28 \%) in our series. Diagnostic imaging modalities possess diverse accuracy rates regarding molecular subtypes. US has been reported to have high PPV in Luminal-like tumors and very high NPV in HER-2 positive and triple-negative subtypes (39). On the other hand, Peppe et al. reported the highest PPV in HER-2 negatives and the highest NPV in HER-2 positives (34). Baumgarten et al. reported a NPV of $75.0 \%$ in triple negative subtypes which was highest in their series of 50 patients, concluding that molecular subtypes affect diagnostic precision of AUS and pathologic outcome (51). In the presented series, PPV of AUS was higher for Luminal like tumors (87.69\%) when compared to HER-2 positive types (33.3\%), whereas NPV was higher for HER-2 positive and triple negative subtypes (100\% and 93.47\%). Accordingly, it is rational to hypothesize that tumor biology guided surgical decision making would be one of the masterpieces of precision medicine in the nearest future when high volume series analyzing the accurate power of diagnostic tools regarding genomic signatures shed valuable light on this issue.

Since predicting the status of axilla after NAT is still a matter of debate, a recent multiparametric nomogram proposed by Kuhn et al. aiming to optimize axillary staging revealed tumor biology was the strongest parameter (52). Our data in accordance with literature supports the current paradigm that tumor biology not only serves the major role in NAT response which is crucial for prognosis but possesses a great value on accurate staging efficiency of diagnostic imaging modality which is a must for optimizing loco-regional surgical decision making.
The presented standard institutional algorithm for patients receiving NAT including dual agent mapping, clipping the confirmed $\mathrm{N} 1$ node(s) and preoperative surgeon performed AUS to demonstrate the pathologic and clipped node provided a SLNB yield in $67.2 \%$ of patients with a median number of 4 SLNs and only $11.06 \%$ of ALND requirement due to clinically obscure disease meaning sparing an large number of cases from the devastating effects of extensive axillary surgery among patients presenting with nodal metastases. Similarly, Mamtani et al. reported that $68 \%$ of the N1 patients became eligible for SLNB after NAT and $48 \%$ of them spared ALND, supporting the role of NAT in reducing the need for ALND (53). In a recent metanalysis by Samiei et al. evaluating diagnostic performance of noninvasive imaging for assessment of axillary response after NAT in cN1 breast cancer revealed similar pooled PPV, and NPV for 18F-FDG PET-CT (78\% and $49 \%$ ) with our series ( $78 \%$ and $53 \%$ ) which is in accordance with the fact that 18F-FDG PET-CT provides more standardized and solid values based on metabolic activity with SUVs (48). Nevertheless, for AUS, the pooled sensitivity, specificity, PPV, and NPV were $65 \%, 69 \%, 77 \%$ and $50 \%$, respectively, all of which were lower than our findings $(83 \%$, $85 \%, 91 \%$ and $73 \%$ ) supporting the crucial importance of the sonographer which might improve the limitations regarding operator dependence. The surgeon performed axillary assessment after NAT via integrating sonography to routine clinical examination not only increases the diagnostic accuracy of US in this setting but might serve to decrease the FNR of SLNB in restaging the axilla via omitting ycN0 patients who are in fact ypN1, on the first hand before surgery.

Regarding possible de-escalation of axillary surgery after NAT, mention should also focus on the debated issue of value of axillary residual tumor burden compared to the status at diagnosis. One of the most important questions to be answered is the importance of detecting ITCs and micrometastases after NAT which is recommended as an absolute 
indication for ALND. In our series $11.06 \%$ of the patients required ALND due to ITCs and micrometastases in SLNB, only $7.14 \%(8 / 28)$ was predicted by AUS and 18-FDG PET-CT which supports the fact that reduced metabolic activity due to lower residual tumor burden might be out of the limits of the diagnostic capacity of these modalities. The response to NAT and the burden of residual disease impacts survival. However, for $\mathrm{cN} 1$ patients before NAT with nodal status ypN0 or ypNITC/mi have been reported to have similar prognosis regarding disease free and overall survival when compared to ypN1-3 disease (54). Moreover, for HER-2 positive and triple negative patients who are excellent responder to NAT, the question of complete omission of axillary surgery for staging deserves consideration. Nevertheless, the prognostic value of microscopic axillary residual disease needs to be addressed via further prospective research, particularly regarding the molecular subtypes.

To date, no non-invasive diagnostic imaging modality has been established as an acceptable alternative to re-stage axilla after NAT and replace SLNB in patients converted or remained clinical and radiologically node negative. As we mentioned above, lower disease burden in the axilla does not reflect as worse prognosis. AUS would be the most preferred modality of choice providing superior results in terms of NPV and FNRs in dedicated and experienced hands and is capable of detecting macrometastasis which is more relevant to prognosis. In the presented series AUS determined macrometastatic disease in $98.18 \%$ and ITCs and micrometastases in $68.18 \%$ cases.

There are various limitations of the presented study. Although the data was collected prospectively according to our institutional protocol, the retrospective nature, single institutional series, relatively short follow-up period and the lack of comparison with other imaging modalities including MRI are the weak sites. Moreover, the integration of newer generation sonographic software's like elastography would have the advantage of decreasing FNR rates and would be the topic of further studies.

\section{Conclusion}

Change is coming to surgical management of axilla and forcing us to reconsider less invasive methods for re-staging. De-escalation of axillary surgery is inevitable just like the more conservative in breast approaches employed in the last three decades. The question is to accurately determine a subgroup of selected patients that we could even omit surgical axillary staging. The replacement of SLNB with a non-invasive counterpart that surpasses the accuracy of SLNB to be a gold standard with superior FNR and NPV, is thus called for. We are stepping into an era of precision medicine and all of the treatment algorithms should be mastered by tumor biology and genomics of each patient. Noninvasive nodal restaging after NAT, particularly in cN1 patients remains as a big puzzle for physicians. However, a profound desire to establish less invasive, more accurate, yet oncologically safe, strategies to predict nodal status persists. Time is up for individualizing management of the axillary nodes after NAT and consider this paradigm change as the prime player in the era of precision medicine. Individual ability, technical skills and experience in AUS with the profound help of artificial intelligence would be able to improve FNR and provide accurate staging after NAT. Until then, surgical assessment seems to continue its leadership in this era.

\section{Conflict of Interests}

No conflict of interests has been declared.

Financial Disclosure: nothing to declare.

\section{Ethics Approval}

Research was conducted according to the ethical guidelines of Helsinki Declaration. Ethics committee approval was not required 
due to the retrospective design of the presented study. The study has institutional approval as a service evaluation.

\section{Acknowledgements}

The study was not funded or sponsored. We would like to thank our colleagues at Zonguldak Bulent Ecevit University The School of Medicine Department of Pathology..

\section{References}

1. Kantor O, Ajmani G, Wang CH, Datta A, Yao K. The Shifting Paradigm for Breast Cancer Surgery in Patients Undergoing Neoadjuvant Chemotherapy. Ann Surg Oncol. 2018;25(1):164-172.

2. Cortazar P, Geyer CE. Pathological complete response in neoadjuvant treatment of breast cancer. Ann Surg Oncol 2015;22:1441-6.

3. Krag D, Harlow S, Julian T. Breast cancer and the NSABP-B32 sentinel node trial. Breast Cancer 2004;11(3):221-4. discussion 64-6.

4. Krag DN, Anderson SJ, Julian TB, Brown AM, Harlow SP, Ashikaga T, et al. National Surgical Adjuvant Breast and Bowel Project. Technical outcomes of sentinel-lymph-node resection and conventional axillary-lymph-node dissection in patients with clinically node-negative breast cancer: resultsfrom the NSABP B-32 randomised phase III trial. Lancet Oncol. 2007;8(10):881-8

5. Krag DN, Anderson SJ, Julian TB, Brown AM, Harlow SP, Costantino JP, et al. Sentinel-lymph-node resection compared with conventional axillarylymph-node dissection in clinically node-negative patients with breast cancer: overall survival findings from the NSABP B-32 randomised phase 3 trial. Lancet Oncol. 2010; 11(10):927-33.

6. Fisher ER, Wang J, Bryant J, Fisher B, Mamounas E, Wolmark N. Pathobiology of preoperative chemotherapy: findings from the National surgical adjuvant breast and bowel (NSABP) protocol B-18. Cancer. 2002;95(4):681-95.

7. Mamounas EP, Brown A, Anderson S, Smith R, Julian T, Miller B, et al. Sentinel node biopsy after neoadjuvant chemotherapy in breast cancer: results from National surgical adjuvant breast and bowel project protocol B-27. J Clin Oncol Off J Am Soc Clin Oncol 2005; 23(12):2694-702

8. Piltin MA, Hoskin TL, Day CN, Davis J, Boughey JC. Oncologic outcomes of sentinel lymph node surgery after neoadjuvant chemotherapy for node-positive breast cancer. Ann Surg Oncol. 2020;27(12):4795-4801.

9. Sávolt Á, Péley G, Polgár C, Udvarhelyi N, Rubovszky G, Kovács E, et al. Eightyear follow up result of the OTOASOR trial: the optimal treatment of the axilla surgery or radiotherapy after positive sentinel lymph node biopsy in early-stage breast cancer: a randomized, single centre, phase III, non-inferiority trial. Eur J Surg Oncol. 2017:43(4):672-679.

10. Galimberti V, Cole BF, Viale G, Veronesi P, Vicini E, Intra M, et al. Axillary dissection versus no axillary dissection in patients with breast cancer and sentinel-node micrometastases (IBCSG 23-01): 10-year follow-up of a randomised, controlled phase 3 trial. Lancet Oncol. 2018;19(10):1385-1393.

11. Amersi F, Giuliano AE. Management of the axilla. Hematol Oncol Clin North Am 2013:27:687.

12. Teshome $\mathrm{M}$, Kuerer HM. Breast conserving surgery and loco-regional control after neoadjuvant chemotherapy. Eur J Surg Oncol. 2017;43(5): 865-874.

13. You S, Kang DK, Jung YS, An YS, Jeon GS, Kim TH. Evaluation of lymph node status after neoadjuvant chemotherapy in breast cancer patients: comparison of diagnostic performance of ultrasound, MRI and (1)(8)F-FDG PET/CT. Br J Radiol. 2015;88(1052): 20150143.

14. Atkins JJ, Appleton CM, Fisher CS, Gao F, Margenthaler JA. Which imaging modality is superior for prediction of response to neo-adjuvant chemotherapy in patients with triple negative breast cancer? J Oncol 2013:2013:964863

15. Humbert 0 , Riedinger JM, Charon-Barra $C$, Berriolo-Riedinger $A$, Desmoulins I, Lorgis V, et al. Clin Cancer Res. Identification of Biomarkers Including 18FDG-PET/CT for Early Prediction of Response to Neoadjuvant Chemotherapy in Triple-Negative Breast Cancer. 2015;21(24):5460.

16. Ellis MJ, Suman VJ, Hoog J, Lin L, Snider J, Prat A, et al. Randomized phase II neoadjuvant comparison between letrozole, anastrozole, and exemestane for postmenopausal women with estrogen receptor-rich stage 2 to 3 breast cancer: clinical and biomarker outcomes and predictive value of the baseline PAM50-based intrinsic subtype--ACOSOG Z1031. J Clin Oncol. 2011; 29(17):2342.

17. Boughey JC, Ballman KV, Hunt KK, McCall LM, Mittendorf EA, Ahrendt GM, et al. Axillary ultrasound after neoadjuvant chemotherapy and its impact on sentinel lymph node surgery: results from the American College of Surgeons Oncology Group Z1071 Trial (Alliance). J Clin Oncol. 2015; 33(30):3386-93.

18. Diepstraten SC, Sever AR, Buckens CF, Veldhuis WB, van Dalen T, van den Bosch MA A J, et al. Value of preoperative ultrasound-guided axillary lymph node biopsy for preventing complete axillary lymph node dissection in breast cancer: a systematic review and meta-analysis. Ann Surg Oncol. 2014;21(1):51-9.

19. Bedi DG, Krishnamurthy R, Krishnamurthy S, Edeiken BS, Le-Petross H, Fornage $\mathrm{BD}$, et al. Cortical morphologic features of axillary lymph nodes as a predictor of metastasis in breast cancer: in vitro sonographic study. AJR Am J Roentgenol. 2008:191(3): 646-52.

20. Koelliker SL, Chung MA, Mainiero MB, Steinhoff MM, Cady B. Axillary lymph nodes: US-guided fine-needle aspiration for initial staging of breast cancer-correlation with primary tumor size. Radiology. 2008;246:81-89.

21. Le-Petross HT, McCall LM, Hunt KK, Mittendorf EA, Ahrendt GM, Wilke LG, et al. Axillary ultrasound identifies residual nodal disease after chemotherapy: results from the American College of Surgeons Oncology group Z1071 Trial (Alliance). AJR Am J Roentgenol. 2018;210(3):669-676.

22. Kim WH, Kim HJ, Park HY, Park JY, Chae YS, Lee SM, et al. Axillary pathologic complete response to neoadjuvant chemotherapy in clinically node-positive breast cancer patients: a predictive model integrating the imaging characteristics of ultrasound restaging with known clinicopathologic characteristics. Ultrasound Med Biol. 2019;45:702-709.

23. Gilardi L, De Cicco C, Colleoni M, Cardillo A, Montagna E, Dellapasqua S, et al. Investigation of 18F-FDG PET in the selection of patients with breast cancer as candidates for sentinel node biopsy after neoadjuvant therapy. Eur J Nucl Med Mol Imaging. 2010;37(10):1834-41.

24. Bevilacqua JL, Kattan MW, Fey JV, Cody HS III, Borgen PI, Van Zee KJ. Doctor, what are my chances of having a positive sentinel node? A validated nomogram for risk estimation. J Clin Oncol. 2007;25(24):3670-9.

25. Giuliano AE, Hunt KK, Ballman KV, Beitsch PD, Whitworth PW, Blumencranz PW, et al. Axillary dissection vs no axillary dissection in women with invasive breast cancer and sentinel node metastasis: a randomized clinical trial. JAMA. 2011;305:569-75,

26. Kuehn T, Bauerfeind I, Fehm T, Fleige B, Hausschild M, Helms G, et al. Sentinel-Iymph-node biopsy in patients with breast cancer before and after neoadjuvant chemotherapy (SENTINA): a prospective, multicentre cohort study. Lancet Oncol. 2013;14:609-18.

27. Boileau JF, Poirier B, Basik M, Holloway CMB, Gaboury L, Sideris L, et al. Sentinel node biopsy after neoadjuvant chemotherapy in biopsy-proven node-positive breast cancer: The SN FNAC study. J Clin Oncol. 2015;33: 258-63.

28. Boughey JC, Suman VJ, Mittendorf EA, Ahrendt GM, Wilke LG, Taback B, et al. Sentinel lymph node surgery after neoadjuvant chemotherapy in patients with node-positive breast cancer: the ACOSOG Z1071 (alliance) clinical trial. JAMA. 2013;310:1455-61.

29. Classe JM, Loaec C, Gimbergues P, Alran S, de Lara CT, Dupre PF, et al. Sentinel lymph node biopsy without axillary lympha denectomy after neoadjuvant chemotherapy is accurate and safe for selected patients: the GANEA 2 study. Breast Cancer Res Treat. 2019;173(2):343-352.

30. Kahler-Ribeiro-Fontana S, Pagan E, Magnoni F, Vicini E, Morigi C, Corso G, et al. Long-term standard sentinel node biopsy after neo-adjuvant treatment in 
breast cancer: a single institution ten-year follow-up. Eur J Surg Oncol. 2021;47(4):804-812. Epub 2020 Oct 15

31. Galimberti V, Cole BF, Zurrida S, Viale G, Luini A, Veronesi P, et al. Axillary dissection versus no axillary dissection in patients with sentinel-node micrometastases (IBCSG 23-01): a phase 3 randomised controlled trial. Lancet Oncol 2013;14(4):297e305

32. Giuliano AE, Hunt KK, Ballman KV, Beitsch PD, Whitworth PW,Blumencranz PW, et al. Axillary dissection vs no axillary dissection in women with invasive breast cancer and sentinel node metastasis: a randomized clinical trial. Jama 2011;305(6):569e75

33. Donker M, van Tienhoven G, Straver ME, Meijnen P, van de Velde CJ, Mansel RE, et al. Radiotherapy or surgery of the axilla after a positive sentinel node in breast cancer (EORTC 10981-22023 AMAROS): randomised, multicentre,open-label, phase 3 non-inferiority trial. Lancet Oncol 2014;15(12):1303e10.

34. Peppe A, Wilson R, Pope R, Downey K, Rusby J. The use of ultrasound in the clinical re-staging of the axilla after neoadjuvant chemotherapy (NACT). Breast 2017;35:104e8

35. Cools-Lartigue J, Meterissian S. Accuracy of axillary ultrasound in the diagnosis of nodal metastasis in invasive breast cancer: a review. World $J$ Surg 2012;36:46

36. Nwaogu IY, Yan Y, Appleton CM, Cyr AE, Margenthaler A. Predictors of false negative axillary ultrasound in breast cancer. J Surg Res. 2015;198(2): 351-4.

37. Houssami N, Ciatto S, Turner RM, Cody 3rd HS, Macaskill P. Preoperative ultrasound-guided needle biopsy of axillary nodes in invasive breast cancer: meta-analysis of its accuracy and utility in staging the axilla. Ann Surg 2011;254(2):243-51.

38. Tucker NS, Cyr AE, Ademuyiwa FO, Tabchy A, George K, Sharma PK, et al. Axillary Ultrasound Accurately Excludes Clinically Significant Lymph Node Disease in Patients With Early Stage Breast Cancer. Ann Surg. 2016; 264(6):1098-1102.

39. Di Micco R, Zuber V, Fiacco E, Carriero F, Gattuso Ml, Nazzaro L, et al. Sentinel node biopsy after primary systemic therapy in node positive breast cancer patients: time trend, imaging staging power and nodal downstaging according to molecular subtype. Eur J Surg Oncol. 2019;45(6):969-975

40. Hieken TJ, Boughey JC, Jones KN, Shah SS, Glazebrook KN. Imaging response and residual metastatic axillary lymph node disease after neoadjuvant chemotherapy for primary breast cancer. Ann Surg Oncol. 2013; 20(10):3199-204

41. Banys-Paluchowski M, Gruber IV, Hartkopf A, Paluchowski P, Krawczyk N Marx M, et al. Axillary ultrasound for prediction of response to neoadjuvant therapy in the context of surgical strategies to axillary dissection in primary breast cancer: a systematic review of the current literature. Arch Gynecol Obstet. 2020;301(2):341-353.

42. Gentilini 0 , Veronesi U . Abandoning sentinel lymph node biopsy in early breast cancer? A new trial in progress at the European Institute of Oncology of Milan (SOUND: Sentinel node vs Observation after axillary UltraSouND). Breast 2012;21:678-81

43. Reimer T, Stachs A, Nekljudova V, Loibl S, Hartmann S, Wolter K, et al. Restricted axillary staging in clinically and sonographically node-negative early invasive breast cancer (c/iT1-2) in the context of breast conserving therapy: first results following commencement of the Intergroup-SentinelMamma (INSEMA) trial. Geburtsh Frauenheilk. 2017;77:149-157.

44. van Roozendaal LM, Vane MLG, van Dalen $T$, van der Hage J A, Strobbe LJA, Boersma LJ, et al. Clinically node negative breast cancer patients undergoing breast conserving therapy, sentinel lymph node procedure versus follow-up: a Dutch randomized controlled multicentre trial (BO0G 2013-08). BMC Cancer. 2017; 17(1):459.

45. Galimberti V, Ribeiro Fontana SK, Maisonneuve P, Steccanella F, Vento AR, Intra $\mathrm{M}$, et al. Sentinel node biopsy after neoadjuvant treatment in breast cancer: five-year follow-up of patients with clinically node-negative or nodepositive disease before treatment. Eur J Surg Oncol 2016;42(3):361e8.

46. Martelli G, Miceli R, Folli S, Guzzetti E, Chifu C, Maugeri I, et al. Sentinel node biopsy after primary chemotherapy in cT2 NO/1 breast cancer patients: longterm results of a retrospective study. Eur J Surg Oncol 2017;43(11): 2012e20.

47. Esqueva A, Siso C, Espinosa-Bravo M, Sobrido C, Miranda I, Salazar JP, Rubio IT. Leveraging the increased rates of pathologic complete response after neoadjuvant treatment in breast cancer to de-escalate surgical treatments. J Surg Oncol. 2021;123(1):71-79. Epub 2020 Oct 1.

48. Samiei S, de Mooij CM, Lobbes MBI, Keymeulen KBMI, van Nijnatten TJA, Smidt ML. Diagnostic Performance of Noninvasive Imaging for Assessment of Axillary Response After Neoadjuvant Systemic Therapy in Clinically Node-positive Breast Cancer: A Systematic Review and Meta-analysis. Ann Surg. 2020 Nov 16. Epub ahead of print.

49. Barron AU, Hoskin TL, Day CN, Hwang ES, Kuerer HM, Boughey JC. Association of low nodal positivity rate among patients with ERBB2positive or triple-negative breast cancer and breast pathologic complete response to neoadjuvant chemotherapy. JAMA Surg. 2018;153(12): 1120-1126.

50. Pilewskie M, Zabor EC, Mamtani A, Barrio AV, Stempel M, Morrow M. The optimal treatment plan to avoid axillary lymph node dissection in early-stage breast cancer patients differs by surgical strategy and tumor subtype. Ann Surg Oncol 2017;24(12): 3527e33.

51. Baumgartner A, Tausch C, Hosch S, Papassotiropoulos B, Varga Z, Rageth $C$, Baege A. Ultrasound-based prediction of pathologic response to neoadjuvant chemotherapy in breast cancer patients. Breast. 2018;39:19-23.

52. Liedtke C, Kolberg HC, Kerschke L, Görlich D, Bauerfeind I, Fehm T, et al. Systematic analysis of parameters predicting pathological axillary status (ypNO vs. ypN+) in patients with breast cancer converting from $\mathrm{cN}_{+}$to ycNO through primary systemic therapy (PST) Clin Exp Metastasis. 2018;35(8): 777-783.

53. Mamtani A, Barrio AV, King TA, Van Zee KJ, Plitas G, Pilewskie M, et al. How Often Does Neoadjuvant Chemotherapy Avoid Axillary Dissection in Patients With Histologically Confirmed Nodal Metastases? Results of a Prospective Study. Ann Surg Oncol. 2016;23(11):3467-3474.

54. van Nijnatten TJ, Simons JM, Moossdorff M, de Munck L, Lobbes MB, van der Pol CC, et al. Prognosis of residual axillary disease after neoadjuvant chemotherapy in clinically node-positive breast cancer patients: isolated tumor cells and micrometastases carry a better prognosis than macrometastases. Breast Cancer Res Treat. 2017;163(1):159-166. 